INTERNATIONAL JOURNAL
OFICAL SCIENCES
PHARMACEUTICAL
RESEARCH

Received on 18 June 2019; received in revised form, 09 February 2020; accepted, 02 April 2020; published 01 May 2020

\title{
FORMULATION AND EVALUATION OF SUSTAINED RELEASE TABLET OF DILTIAZEM HYDROCHLORIDE
}

Vaquar Ahmed ${ }^{*}{ }^{1}$, Saurabh Sharma ${ }^{1}$ and Pankaj Bhatt ${ }^{2}$

Vivek College of Technical Education ${ }^{1}$, Bijnor - 246701, Uttar Pradesh, India.

School of Pharmacy ${ }^{2}$, Glocal University, Saharanpur - 247121, Uttar Pradesh, India.

Keywords:

Sustained-release, Diltiazem $\mathrm{HCl}$, Hydroxypropyl methylcellulose, Povidone, Direct compression

\section{Correspondence to Author:}

Vaquar Ahmed

Vivek College of Technical

Education, Bijnor - 246701, Uttar

Pradesh, India.

E-mail: vaquar2016@gmail.com
ABSTRACT: Diltiazem $\mathrm{HCl}$ is a calcium ion channel inhibitor. The capacity to hinder the convergence of calcium ion present in of cardiac and vascular smooth muscle during membrane depolarization is accepted to be its therapeutic impact. It is broadly utilized in the treatment of a few kinds of cardiovascular disorders. For accomplishing better drug viability, unwavering quality success within the leading edge pharmaceutical structure, and targeted analysis, sustained-release drug delivery has touched toward changing into gauges. The biggest offer of drug delivery frameworks, for example, up to $80 \%$ of all the medication records to the OSRDD (Oral Sustained Release Drug Delivery). Sustained releases tablets of diltiazem $\mathrm{HCl}$ was planned to utilize Hydroxypropyl methylcellulose (HPMC 643), and povidone in various ratios, the extended-release conduct of fabricated tablets were then assessed. Sustained-release diltiazem $\mathrm{HCl}$ tablets were made by the direct compression method. The formulation was streamlined based on various tablet properties and drug release design in-vitro release profile. The subsequent formulation created tablets with required hardness, weight uniformity, and friability. The aftereffect of in-vitro dissolution study demonstrated that formulation F5 is the most suitable formulation as it displays drug release design for any longer period of time. An increase in the drug release profile of the drug was seen on expanding polymer proportion.
INTRODUCTION: The expression "Drug Delivery" covers an extremely broad scope of systems used to deliver therapeutic agents into the human body. Drugs are controlled with a fundamental point of relieving patient sicknesses. Drugs are never directed in their unadulterated structure yet are changed over in an appropriate formulation with the goal that its beginning and power of action just as absolute duration of action can be checked ${ }^{1}$.

\begin{tabular}{|l|}
\hline QUICK RESPONSE CODE \\
\hline DOI: \\
DOI link: http://dx.doi.org/10.13040/IJPSR.0975-8232.11(5).2193-98 \\
\hline
\end{tabular}

Drugs are once in a while controlled as unadulterated chemical substances alone and are constantly given as detailed preparations or medicines (for example, drug delivery frameworks or measurement shapes). These can change from moderately basic answers for complex drug delivery frameworks using suitable additives or excipient in the formulations. It is the formulation excipient, solubility, suspend, additives that modify solvency, suspend, thicken, preserve, emulsify, modify dissolution, improve the compressibility, and flavor drug substances to frame different preparations. Before a drug substance can be effectively figured into the structure of the measurement, numerous variables must be considered. These can be extensively gathered into the accompanying three classifications ${ }^{2}$. 
- Biopharmaceutical considerations, including variables influencing the absorption of the drug substance from various administration courses.

- Drug factors, for example, the physical and chemical properties of the drug substance.

- Therapeutic considerations, including thought of the clinical sign to be dealt with and patient elements.

In traditional drug treatment, it tends to be seen that the administration of a drug by either intravenous infusion or an extra-vascular route, for example, orally, intramuscularly, or rectally does not keep up drug blood level inside the therapeutic range for an all-encompassing period of time. The short action is because of the powerlessness of conventional dosage forms to control temporal delivery ${ }^{3}$. Oral drug delivery is the most favored course of the different drug molecules among every single other course of drug delivery due to the simplicity of administration, patient compliance, and flexible structure of dose structure ${ }^{4}$. Drug discharge is the procedure by which a drug leaves a drug item and is exposed to absorption, distribution, metabolism, and excretion, in the long run, to getting to be accessible for pharmacological action 5 . Presently multi-day customary measurement types of drugs are quickly being supplanted by the new and the novel drug delivery frameworks. Among, these the controlled discharge/sustained release drug delivery systems have turned out to be incredibly famous in present-day therapeutics ${ }^{6}$.

The regular measurement structures are quickly supplanted by this novel's sustained discharge procedures. The terms Sustained Release, Delayed Release or Prolong Release formulations are utilized to recognize drug delivery systems that are intended to accomplish or expand therapeutic impact by ceaselessly discharging medicine over an all-encompassing period of time after administration of a unit dose ${ }^{7}$. Any drug or measurement structure adjustment that draws out the therapeutic action of the drug ${ }^{8}$. The arrival of the drug is hindered for a postponed and delayed period of time in the fundamental circulation 9 . Sustained Release formulation keeps up a uniform drug level in blood with better patient compliance just as expanded adequacy of drug ${ }^{10}$. Sustained discharge tablets are commonly taken more than once per day during a course of treatment, though in conventional drug delivery systems, there is have to take 3-4 times dose in multi-day to accomplish a similar therapeutic action ${ }^{11}$.

Diltiazem hydrochloride is a Calcium channel foe and broadly utilized in the treatment of specific kinds of cardiovascular issues. The therapeutic impacts of Diltiazem hydrochloride are identified with its capacity to hinder the flood of calcium particles in cardiovascular and vascular smooth muscle during membrane depolarization. A basic dosing plan with more than once every day administration of the antihypertensive agent is known to expand patient compliance ${ }^{12,13}$.

Here in this investigation, the all-inclusive discharge tablets were set up by a direct compression strategy. Direct compression ${ }^{13,14}$ is a favored strategy for the readiness of tablets as it offers a few points of interest like:

i. It is prudent contrasted with wet granulation since it requires less unit activity ${ }^{15,16}$.

ii. Progressively appropriate for dampness and warmth delicate APIs ${ }^{17,18}$.

iii. Changes in the dissolution profile do not happen on long haul storage ${ }^{19,20}$.

Direct compression excipients, for the most part, incorporate diluents, fasteners, and break down. The all-inclusive formulation Diltiazem hydrochloride were planned by utilizing Hydroxypropyl methylcellulose (HPMC 643) and povidone in various proportions, the allencompassing discharge conduct of fabricated tablets were then explored. The present research try was coordinated towards the improvement of an all-inclusive discharge tablet formulation containing diltiazem $\mathrm{HCl}$ to be taken once instead of numerous times a day ${ }^{21,22}$.

\section{MATERIALS AND METHODS:}

Material: Diltiazem hydrochloride API and HPMC 643 was received as a gift sample from Modimudi Pharmaceuticals Meerut. All other ingredients used were of Pharmaceutical grade. 


\section{Method:}

Preparation of Diltiazem HCl Extended Release Tablet by Direct Compression Method: The comprehensive discharge tablets of Diltiazem $\mathrm{HCl}$ were set up by direct compression methodology. Five novel definitions were set up for Diltiazem $\mathrm{HCl}$ expanded discharge tablet with different structure of polymer and excipients proportion. All of the fixings (except for magnesium stearate and talc) were gone at first through sieve \# 120, and after that, absolutely weighed, mixed totally, and after that experienced sieve \# 40. The powder blend was then dried in a hot air oven at $50{ }^{\circ} \mathrm{C}$ for $20-30$ min, before punching the powder were lubricated with magnesium stearate and talc, by then punched in a multi tooling lab-based 8 station turning punching machine (SHAKTI) in a continuous speed with high compression capacity to abstain from topping.

TABLE 1: FORMULATION OF DILTIAZEM

\begin{tabular}{ccccccc}
\hline S. no. & Ingredients & F1 & F2 & F3 & F4 & F5 \\
\hline 1 & Diltiazem HCl & $120 \mathrm{mg}$ & $120 \mathrm{mg}$ & $120 \mathrm{mg}$ & $120 \mathrm{mg}$ \\
2 & Wheat starch & $35 \mathrm{mg}$ & $35 \mathrm{mg}$ & $35 \mathrm{mg}$ & $25 \mathrm{mg}$ \\
3 & Tragacanth & $15 \mathrm{mg}$ & $15 \mathrm{mg}$ & $15 \mathrm{mg}$ & $5 \mathrm{mg}$ & $25 \mathrm{mg}$ \\
4 & Talc & $15 \mathrm{mg}$ & $15 \mathrm{mg}$ & $15 \mathrm{mg}$ & $5 \mathrm{mg}$ & $5 \mathrm{mg}$ \\
5 & Magnesium stearate & $5 \mathrm{mg}$ & $5 \mathrm{mg}$ & $5 \mathrm{mg}$ & $5 \mathrm{mg}$ & $5 \mathrm{mg}$ \\
6 & Lactose: fructose $(1: 1)$ & $100 \mathrm{mg}$ & $100 \mathrm{mg}$ & $100 \mathrm{mg}$ & $100 \mathrm{mg}$ & $100 \mathrm{mg}$ \\
7 & HPMC643 & $60 \mathrm{mg}$ & $70 \mathrm{mg}$ & $50 \mathrm{mg}$ & $80 \mathrm{mg}$ & $90 \mathrm{mg}$ \\
8 & Povidone & $40 \mathrm{mg}$ & $30 \mathrm{mg}$ & $50 \mathrm{mg}$ & $50 \mathrm{mg}$ & $40 \mathrm{mg}$ \\
9 & Total & $390 \mathrm{mg}$ & $390 \mathrm{mg}$ & $390 \mathrm{mg}$ & $390 \mathrm{mg}$ & $390 \mathrm{mg}$ \\
\hline
\end{tabular}

Evaluation of Tablets: Prepared tablets were evaluated for certain properties like tablet weight variation, assay, hardness, friability, dissolution study, etc.

Pre-compression Parameters: Pre-compression parameters of tablet powder blends such as bulk density, tapped density, carr's index, compressibility index, and Hausner ratio were calculated

Post-compression Parameters: The postcompression parameters for various batches were evaluated accordingly, such as tablet weight variation, hardness, friability, disintegration, invitro dissolution study.

Assay: Tablets containing $120 \mathrm{mg}$ diltiazem $\mathrm{HCl}$ were weighted; powdered and average weight was calculated. Powder equivalent to $10 \mathrm{mg}$ of diltiazem was dissolved in $30 \mathrm{ml}$ of $0.1 \mathrm{~N} \mathrm{HCl}$ solution with the help of sonication. This was further diluted up to the mark with the same solvent. The solution was filtered, and the first $5 \mathrm{ml}$ of the filtrate was discarded. This solution was further diluted to obtain a $10 \mu \mathrm{g} / \mathrm{ml}$ solution with the same solvent and subjected to UV analysis.

Hardness: The hardness of tablets is defined as "the force required in breaking a tablet," and it is determined using a Monsanto hardness testing apparatus. The tablet is placed vertically in the tester, and the force required to break the tablet was measured.

Friability: The friability of tablets was measured in a Roche friabilator. Twenty tablets of known weight (Wo) were taken in a drum for a fixed time (100 revolutions) and weight (W) again. Percentage friability was calculated from the loss in weight, as given in the equation below. The weight loss should not be more than $1 \% \mathrm{w} / \mathrm{w}$.

$$
\% \text { friability }=(\mathrm{Wo}-\mathrm{W}) / \mathrm{Wo} \times 100
$$

In-vitro Comparative Dissolution Study: In-vitro drug release of the tablets was conducted for a period of $6 \mathrm{~h}$ using a six-station USP type II (paddle) apparatus at $37{ }^{\circ} \mathrm{C} \pm 0.5{ }^{\circ} \mathrm{C}$ and $50 \mathrm{rpm}$ speed. The dissolution studies were carried out in acid buffer $\mathrm{pH} 1.2$ for the first $2 \mathrm{~h} .1 \mathrm{ml}$ sample was withdrawn in $10 \mathrm{ml}$ volumetric flask at a specific interval of time from dissolution medium and replaced with fresh medium to maintain a constant volume. The withdrawn sample was made up of the mark with the same medium and was analyzed at $232.5 \mathrm{~nm}$; the amount of drug present in the sample was calculated.

Drug Content Uniformity: For the content uniformity test, five tablets were weighed and pulverized to a fine powder. A quantity of powder 
equivalent to one dose of the drug was extracted into standard media, and it was centrifuged for 10 min at $4000 \mathrm{rpm}$. The supernatant was collected. The drug content was determined by measuring the absorbance using UV- spectrophotometer after appropriate dilution with the same media. The mean percent drug content was calculated as an average of three determinations.

Thickness: The thickness of tablets was measured in $\mathrm{mm}$ by using Vernier caliper. The 20 tablets were selected randomly; the thickness of individual tablet and the average thickness of the tablets was noted

\section{RESULTS AND DISCUSSION: \\ Pre-Formulation Studies:}

Calibration Curve of Diltiazem HCl: The calibration curve was prepared in $0.1 \mathrm{~N} \mathrm{HCl}$. In 0.1 $\mathrm{N} \mathrm{HCl}$, the slope of the graph was found to be 0.0837 and with regression coefficient $R^{2}=0.9412$.

FTIR Spectrum of Diltiazem HCl: The FTIR spectroscopy was performed for the identification of pure drug a. The spectra obtained in Fig. 2 from the FTIR spectrophotometer in the range 400-4000 $\mathrm{cm}^{-1}$ is of pure drug, and that in Fig. 3 is a drug with excipients that showed similar/almost similar peaks as that of the pure drug, i.e., for $\mathrm{C}-\mathrm{H}, \mathrm{N}-\mathrm{H}$, and $\mathrm{C}-\mathrm{O}$ stretch. This indicates no modification and interaction between drug and excipients.
TABLE 2: VALUES OF CONENCETRATION AND ABSORBANCE AT $237 \mathrm{~nm}$

\begin{tabular}{ccc}
\hline S. no. & Concentration in $\mathbf{~ m c g / m l ~}$ & Absorbance \\
\hline 1 & 0 & 0 \\
2 & 2 & $0.116 \pm 0.002$ \\
3 & 4 & $0.224 \pm 0.003$ \\
4 & 6 & $0.332 \pm 0.004$ \\
5 & 8 & $0.434 \pm 0.001$ \\
6 & 10 & $0.536 \pm 0.001$ \\
\hline
\end{tabular}

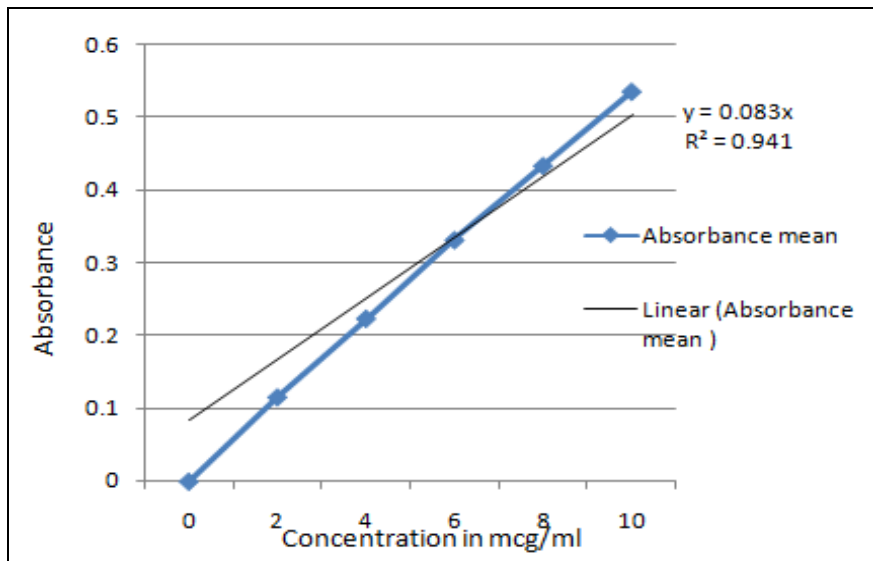

FIG. 1: STANDARD CALIBRATION CURVE OF DILTIAZEM HCI IN 0.1N HCI

\begin{tabular}{|c|c|c|c|c|}
\hline Formulation & $\begin{array}{c}\text { Thickness } \\
\text { (mm) }\end{array}$ & $\begin{array}{c}\text { Hardness } \\
\left(\mathrm{kg} / \mathrm{cm}^{2}\right)\end{array}$ & $\begin{array}{c}\text { Friability } \\
\%\end{array}$ & $\begin{array}{c}\text { Drug } \\
\text { content } \%\end{array}$ \\
\hline F1 & 4.11 & 4.9 & 0.32 & 99.82 \\
\hline $\mathrm{F} 2$ & 4.12 & 5.2 & 0.27 & 99.28 \\
\hline F3 & 4.14 & 5.7 & 0.20 & 98.37 \\
\hline $\mathrm{F} 4$ & 4.13 & 6.2 & 0.18 & 98.95 \\
\hline F5 & 4.15 & 6.6 & 0.20 & 99.10 \\
\hline
\end{tabular}

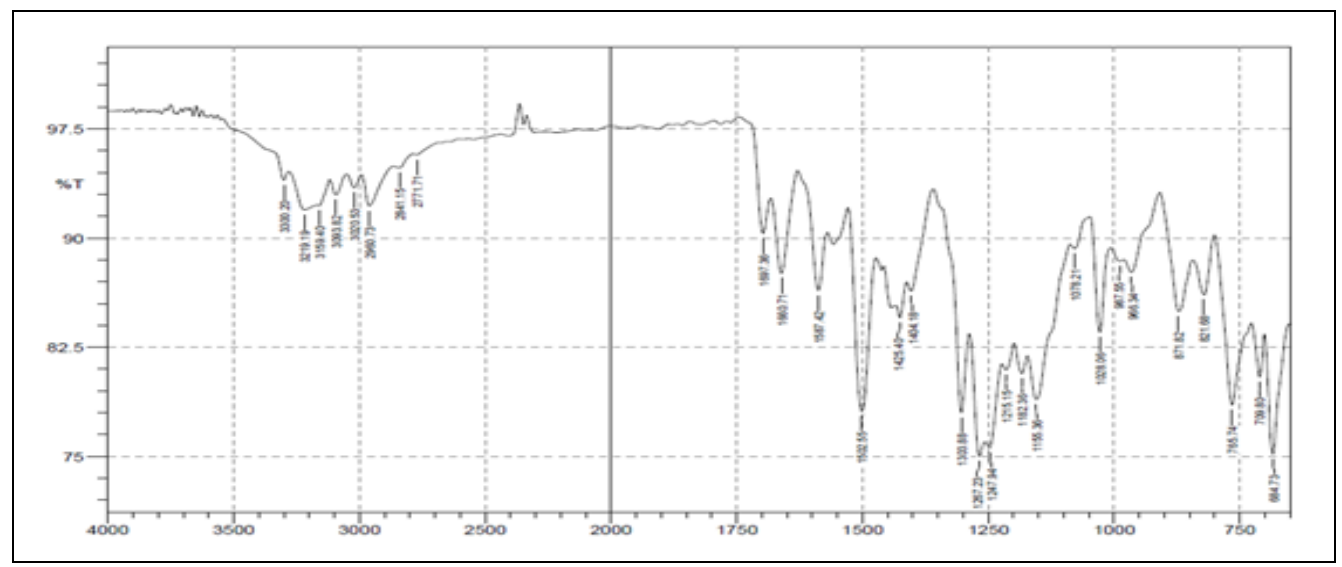

FIG. 2: FTIR SPECTRA OF PURE DILTIAZEM DRUG

TABLE 4: EVALUATION OF POWDER BLENDS OF DIFFERENT COMPOSITIONS OF DILTIAZEM HCI TABLET

\begin{tabular}{cccccc}
\hline Formulation & $\begin{array}{c}\text { Angle of repose } \\
(\boldsymbol{\theta}) \text { in }{ }^{\circ}(\mathbf{d e g r e e})\end{array}$ & $\begin{array}{c}\text { Bulk density } \\
(\mathbf{g m} / \mathbf{m l})\end{array}$ & $\begin{array}{c}\text { Tapped density } \\
(\mathbf{g m} / \mathbf{m l})\end{array}$ & $\begin{array}{c}\text { Carr's index } \\
(\boldsymbol{\%})\end{array}$ & $\begin{array}{c}\text { Hausner's } \\
\text { ratio }\end{array}$ \\
\hline F1 & 18.25 & 0.525 & 0.593 & 11.30 & 1.22 \\
F2 & 17.85 & 0.475 & 0.498 & 11.80 & 1.11 \\
F3 & 14.22 & 0.402 & 0.480 & 10.96 & 1.18 \\
F4 & 13.64 & 0.665 & 0.725 & 10.45 & 1.13 \\
F5 & 15.80 & 0.410 & 0.503 & 11.10 & 1.25 \\
\hline
\end{tabular}


Comparative in-vitro Dissolution Study of Different Formulations of Diltiazem Sustained Release Tablet:

TABLE 5: IN-VITRO DISSOLUTION STUDY

\begin{tabular}{cccccc}
\hline Time (h) & F1 & F2 & F3 & F4 & F5 \\
\hline 0 & 0 & 0 & 0 & 0 & 0 \\
0.5 & 24.20 & 26.02 & 25.56 & 16.57 & 24.27 \\
01 & 32.10 & 38.98 & 40.12 & 23.24 & 35.98 \\
02 & 43.26 & 41.29 & 41.99 & 34.92 & 43.01 \\
04 & 57.91 & 54.96 & 55.56 & 47.32 & 57.00 \\
06 & 63.36 & 65.11 & 62.65 & 52.11 & 68.18 \\
08 & 78.11 & 78.66 & 76.11 & 64.84 & 77.4 \\
10 & 82.15 & 81.31 & 85.01 & 72.34 & 83.14 \\
12 & 97.64 & 95.21 & 97.64 & 81.94 & 94.21 \\
\hline
\end{tabular}

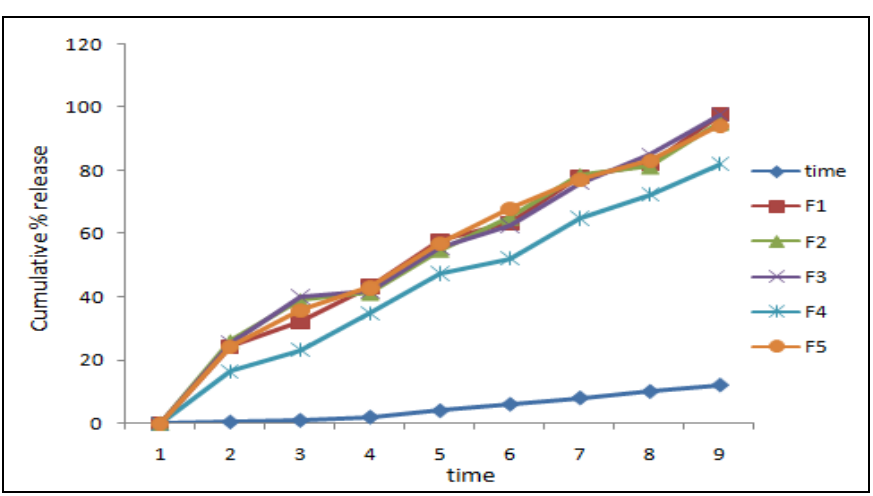

FIG. 3: CUMULATIVE \% RELEASE $v s$. TIME

DISCUSSION: Diltiazem $\mathrm{HCl}$ tablets were figured by direct compression method using wheat starch, Tragacanth, Talc, Magnesium stearate, Lactose: fructose (1:1), HPMC 643 and Povidone for creating controlled release solid dosage structure. The granules were subjected to various pre formulation study tests before compression and are shown in Table 4. The angle of repose from plan F1 to F5 changed between 13.64 to 18.25 , showing excellent flow properties. The tapped density shifted from 0.480 to 0.725 , while bulk density went from 0.402 to 0.665 , both showing great flowability of powder blends. Carr's list and Hausner's ratio went between 10.45-11.80 and 1.11-1.25, respectively, which also describes the great flow property of powders. The punched tablets of various detailing were also subjected to several assessment parameters like tablet weight variation, assay, hardness, friability, dissolution study, and so forth, which is shown in Table 3. Every one of the tablets passed weight variation test as every one of them weighed inside given pharmacopoeial limits. The hardness of tablets extended between 4.9 to 6.6 , which demonstrated great mechanical strength and ability to withstand physical pressure and stress. The friability was between 0.18 to 0.32 , which is inside limits and shows great resistance of tablets to mechanical stress. The percent medication substance of tablets was inside permissible limits; for example, $98.37 \%$ to $99.82 \%$.

The medication release profile of all the definition was given in Table 5 and Fig. 3. The thickness of tablets was observed to be 4.12 to $4.15 \mathrm{~mm}$, which shows uniform thickness due to uniform die fill. Among every one of the formulations plans, F5 was found to have a better release profile when contrasted with others. The detailing F5 showed release in 8 hours as per USP dissolution criteria for expanded release diltiazem $\mathrm{HCl}$ tablet.

CONCLUSION: The general examination was done to plan and assessed Diltiazem sustainedrelease tablet utilizing diverse polymer ratio, and the present investigation demonstrated that it tends to be effectively planned to utilize direct compression technique for moderate release, improved bioavailability, patient compliance with effective therapy. Every one of the details demonstrated satisfactory release, among which F5 was best chosen out. In light of the result, it was presumed that the detailing F5 demonstrates hardness $6.6 \mathrm{~kg} / \mathrm{cm}^{2}$, friability was $20 \%$, drug content $99.10 \%$, and thickness of the tablet was $4.13 \mathrm{~mm}$. The investigation uncovered that HPMC 643 and povidone could be utilized in the various ratio for a superior expanded profile. More the concentration of polymer delay in the release profile was watched.

It was likewise inferred that the drug release was significantly affected by the idea of the polymer joined in the plans. The future extent of this work can be useful for planning sustained-release tablets with natural materials as wheat starch, tragacanth on account of simple accessibility, non-toxicity, non-irritant, cost-effective, and simplicity of preparation method. These frameworks will be favorable for those patients who have a long haul of chronic disease and additionally help in improving the bioavailability of drugs.

ACKNOWLEDGEMENT: Nil

CONFLICTS OF INTEREST: Nil 


\section{REFERENCES:}

1. Agarwal G and Agarwal S: Oral sustained release tablet: an overview with special emphasis on matrix table. American journal of advanced drug delivery 2017.

2. Xuan D, Adam WKA and Joseph RR: Extended-release and targeted drug delivery systems. In: Gennaro AR, ed. Remington: The Science and Practice of Pharmacy. New Delhi, India: Wolters Kluwer Health (India) Pvt. Ltd; 2007: 939-64.

3. Chein YW: Novel Drug Delivery System. Revised and expanded .2nd ed.NewYork: Marcel Dekker Inc 2005

4. Kamboj S, Saroha K, Goel M and Madhu C: Sustained release drug delivery system: an overview. Journal of Pharmaceutics 2013; 1: 169-81.

5. Zameerudin M, Namdev H, Jhadav SB, Kadam VS and Bade A: Recent advances of sustained release oral drug delivery system: a review. International Journal of Pharmaceutical Sciences and Biomedical Sciences 2014; 3: $1479-89$.

6. Ratilal D and Priti DG: An overview on sustained release drug delivery system. International Journal of Research and Applied Pharmaceutics 2011; 1701-08.

7. Patil K, Patel MS, Narayana SB and Patel L: An overview on extended release matrix technology. Journal of Pharmaceutics 2013; 828-42.

8. Gandhi A and Kumar SL: Recent trends in sustained release drug delivery system. International Journal of Applied Pharmaceutics 2014; 1: 122-34.

9. Bhankar SK, Chaudhari AV, Mahale NB and Chaudhari SR: A review on oral dispersible tablets prepared using sustained release microparticles. Journal of Advanced Release Drug Delivery System 2014; 1: 82-95.

10. Semwal A, Singh R and Kakar S: Drug release characteristics of dosage forms: a review. Journal of Coastal Life Medicine 2014; 332-36.

11. Kumar P and Kijjal R: Novel oral sustained release drug technology: a concise review. International Journal of Research and Development Pharmaceutical Sciences 2013; 2: 262-69.

12. Alexander A and Singh A: Herbal drugs used for the treatment of asthma: An overview. Int J Cur Biomed Phar Res 2011; 1(2): 67-79.
13. Amarji B, Raghuwanshi D, Vyas SP and Kanaujia P: Lipid nano spheres (LNSs) for enhanced oral bioavailability of amphotericin B: development and characterization. Journal of Biomedical Nanotechnology 2007; 3(3): 264-69.

14. Angare D, Giri T, Tripathi DK and Ajazuddin: Unexplored areas and new findings in lipid emulsion serving as a potential drug carrier for lipophilic drugs: a review. Trends Med Res 2012.

15. Senthil BK, Prem ADC, Senthil KKL, Saravanakumar M and Thirumurthy $\mathrm{R}$ : formulation and evaluation of diltiazem hydrochloride extended release tablets by meltgranulation technique. IJPIR 2011; 1(1): 211-21.

16. Rohan DK and Sugandha VM: UV Spectrophotometric Estimation of Diltiazem Hydrochloride in bulk and tablet dosage form. World Journal of Pharmaceutical Sciences. 2011; 3(9): 634-41

17. Dewangan D, Kumar T, Alexander A, Nagori $\mathrm{K}$ and Tripathi DK: Pyrazole: their chemistry and pharmacological potentials: a review. Current Pharma Research 2011; 1(4): 369-77.

18. Badwaik HR, Sakure K, Nakhate KT, Dhongde H, Kashyap P and Tripathi DK: Microwave assisted ecofriendly synthesis, characterization and in-vitro release behavior of carboxymethyl xanthan gum. Curr Microwave Chem. 2015; Doi: 10.2174/2213335602666151022203648

19. Giri TK, Choudhary C, Alexander A, Tripathy M and Tripathy DK: Sustained release of diltiazem hydrochloride from cross-linked biodegradable IPN hydrogel beads of pectin and modified xanthum gum. Indian Journal of Pharmaceutical Sciences. 2013.

20. Giri TK, Kumar K, Alexander A, Tripathy M, Tripathi DK, Novel controlled release solid dispersion for the delivery of diclofenac sodium. Current Drug Delivery. 2013

21. Giri TK, Thakur D, Alexander A, Tripathi M, Tripathi D.K Biodegradable IPN hydrogel beads of pectin and grated alginate for controlled delivery of diclofenac sodium. Journal of MaterialsScience: Materials in Medicine, 2016

22. Giri T.K, Verma S, Alexander A, Tripathy M, Tripathi D.K, Crosslinked biodegradable alginate hydrogel floating beads for stomach site specific controlled drug delivery of Metronidazole. Farmacia, 2013.

How to cite this article:

Ahmed V, Sharma S and Bhatt P: Formulation and evaluation of sustained release tablet of diltiazem hydrochloride. Int J Pharm Sci \& Res 2020; 11(5): 2193-98. doi: 10.13040/IJPSR.0975-8232.11(5).2193-98.

All @ 2013 are reserved by the International Journal of Pharmaceutical Sciences and Research. This Journal licensed under a Creative Commons Attribution-NonCommercial-ShareAlike 3.0 Unported License.

This article can be downloaded to Android OS based mobile. Scan QR Code using Code/Bar Scanner from your mobile. (Scanners are available on Google Playstore) 